\title{
ECMO improves survival following cardiogenic shock due to carbon monoxide poisoning - an experimental porcine model
}

\author{
Carsten Simonsen ${ }^{1,2^{*}}$ (D), Sigridur O. Magnusdottir ${ }^{2,3}$, Jan J. Andreasen ${ }^{1,2}$, Marianne Cathrine Rohde ${ }^{4}$ \\ and Benedict Kjærgaard ${ }^{1,2,3}$
}

\begin{abstract}
Background: Severe intoxication with carbon monoxide (CO) is extremely lethal and causes numerous deaths due to cardiac or respiratory failure. Conventional intensive treatment may not be sufficient. The aim of this study was to investigate the treatment effect of extracorporeal veno-arterial extracorporeal membrane oxygenation (ECMO) following severe $\mathrm{CO}$ poisoning in an experimental porcine model.

Methods: A total of twelve pigs were anaesthetized, routinely monitored and intoxicated by inhalation of CO until the beginning of cardiac failure and randomized to a treatment (ventilator using an $\mathrm{FiO}_{2}$ of $100 \%$ or $\mathrm{ECMO}$ ). In the case of cardiac arrest, advanced resuscitation using standard guidelines was performed for at least $10 \mathrm{~min}$. ECMO was also initiated in the ventilation group if the return of spontaneous circulation did not occur within 10 min. Lung tissue biopsies were obtained before and after CO intoxication.

Results: All animals in the ECMO group survived; however, one had to be resuscitated due to cardiac arrest. A single animal survived in the ventilator group, but five animals suffered from cardiac arrest at an average of 11.8 min after initiation of treatment. Conventional resuscitation failed in these animals, but four animals were successfully resuscitated after the establishment of ECMO.

A significant decrease was noticed in $\mathrm{PO}_{2}$ with increasing $\mathrm{HbCO}$, but there was no increase in pulmonary vascular resistance. No differences in H\&E-stained lung tissue biopsies were observed.
\end{abstract}

Conclusions: The use of ECMO following severe CO poisoning greatly improved survival compared with conventional resuscitation in an experimental porcine model. This study forms the basis for further research among patients.

Keywords: Carbon monoxide poisoning, Smoke poisoning, Extracorporeal membrane oxygenation, Hyperbaric oxygenation, Cardiac failure, Respiratory failure, Pulmonary vascular resistance

\section{Introduction}

Carbon monoxide (CO) is extremely treacherous; invisible and without smell or taste, this lethal gas overtakes people without warning. Negligible $\mathrm{CO}$ concentrations occur in the atmosphere, but large amounts of $\mathrm{CO}$ form during the insufficient combustion of organic material, and a primary risk of exposure is the inhalation of smoke from fires [1]. Other significant sources of $\mathrm{CO}$

\footnotetext{
* Correspondence: carsten.simonsen@rn.dk

${ }^{1}$ Department of Cardiothoracic Surgery, Aalborg University Hospital, Hobrovej 18-22, 9000 Aalborg, Denmark

${ }^{2}$ Department of Clinical Medicine, Aalborg University, Sdr. Skovvej 15, 9000

Aalborg, Denmark

Full list of author information is available at the end of the article
}

poisoning include residential heat sources, suicide/attempts and occupational exposure [2-5].

Approximately 50,000 annual contacts with emergency departments in the US are due to $\mathrm{CO}$ poisoning, resulting in approximately 2700 deaths [6, 7]. Surviving patients may suffer from increased risk of developing neurological symptoms, e.g., extrapyramidal symptoms, encephalopathy and cardiac insufficiency [8-10].

The rationale behind all currently established treatments for $\mathrm{CO}$ poisoning is to elevate the partial pressure of oxygen in the blood, favouring the formation of $\mathrm{HbO}_{2}$ instead of $\mathrm{HbCO}$, and to increase the oxygen content in the blood [11, 12]. In mild cases, this is achieved by

(c) The Author(s). 2018 Open Access This article is distributed under the terms of the Creative Commons Attribution 4.0 International License (http://creativecommons.org/licenses/by/4.0/), which permits unrestricted use, distribution, and 
administering supplementary normobaric oxygen (NBO) for inhalation. In more severe cases, hyperbaric oxygen treatment $(\mathrm{HBO})$ is used [11]. HBO can further increase blood oxygen content, resulting in a decreased half-life of $\mathrm{HbCO}$, but the protocol for when to offer $\mathrm{HBO}$ differs greatly internationally [13].

$\mathrm{CO}$ poisoning may have a profound effect on both respiratory and cardiac function, but although $\mathrm{HBO}$ increases blood oxygen tension and decreases $\mathrm{HbCO}$ half-life, the benefits of $\mathrm{HBO}$ remain highly debated [14-17]. Conventional intensive treatment methods may not be sufficient, and the aim of the present study was to investigate the treatment effect of extracorporeal veno-arterial extracorporeal membrane oxygenation (ECMO) following severe $\mathrm{CO}$ poisoning in an experimental porcine model. The porcine model was chosen due to the close resemblance between porcine and human anatomy/physiology [18]. We hypothesized that (ECMO) would improve survival.

\section{Methods}

\section{Ethical statement}

This study was carried out in accordance with Danish and European legislation regarding the use of animals for research purposes. The experiments were approved by the Danish Animal Experiments Inspectorate (J.nr. 2016-15-0201-01064). At all times, a veterinarian was present, and all participants had training in laboratory animal science prior to experimentation.

\section{Experimental animals and instrumentation}

All experiments were carried out at the Biomedical Research Laboratory at Aalborg University Hospital, Denmark. The research animals were 12 female pigs (Danish Landrace) with an average weight of $48 \mathrm{~kg}$ (range $45-51 \mathrm{~kg}$ ) and approximately 90 days old. The animals were housed in nearby boxes at the laboratory for acclimatization up to 7 days prior to the experiment. During this period, the animals had access to food/water and were attended to by laboratory staff several times each day. Premedication with Zoletil, an anaesthetic combination drug containing equal concentrations of Tiletamine and Zolazepam, was used. Anaesthesia, which was similar in both study groups, was maintained with continuous intravenous infusion of fentanyl and propofol based on weight, with minor adjustments to ensure that anaesthesia was sufficient. The animals were intubated using a 6.5-mm cuffed endotracheal tube and connected to a ventilator (Dameca DREAM, Rødovre, Denmark). Tidal volume was calculated using $8 \mathrm{~mL} / \mathrm{kg}$ and the respiratory rate (RR) was adjusted according to blood $\mathrm{CO}_{2}$ levels $(14-17 / \mathrm{min})$ and reduced whenever ECMO was running. $\mathrm{FIO}_{2}$ was set at the lowest level possible while still achieving blood $\mathrm{PO}_{2}$ levels within a normal range. To avoid atelectasis, positive end-expiratory pressure (PEEP) was fixed at five $\mathrm{cm}_{2} \mathrm{O}$ and recruitment was performed regularly by increasing PEEP to $10-15 \mathrm{~cm}$ $\mathrm{H}_{2} \mathrm{O}$. A small venous catheter was placed in one ear vein to facilitate the infusion of fentanyl and propofol as primary anaesthesia during the remainder of the experiment. Throughout the experiment, fluid was administered according to existing guidelines for porcine anaesthesia $[19,20]$. A bladder catheter with a thermal sensor was inserted and used for monitoring diuresis and core temperature. To detect any possible arrhythmias, constant electrocardiography was performed. Real-time arterial pressure measurements were achieved using an arterial catheter connected to a pressure transducer inserted into the right carotid artery. The same catheter was used for drawing blood for analysis.

After a full sternotomy, arterial catheters were inserted into the pulmonary artery and the left atrium to measure pressure differences over the pulmonary vascular system. The catheters were also used for drawing blood for analysis. Using an articulating dissection instrument (Wolf Lumitip Dissector ${ }^{\mathrm{rm}}$, AtriCure, Mason, Ohio, US)-modified for multiple use as a guide, a division of the fibrous tissue connecting the aorta and the pulmonary artery was made, allowing for the placement of a sonography probe (16-18 mm, MediStim, Copenhagen, Denmark) around the main pulmonary artery. The probe was connected to a flow monitor (MediStim, Copenhagen, Denmark), enabling real-time measurements of the cardiac output.

The flow through the main pulmonary artery was used as cardiac output and for calculating the pulmonary vascular resistance (PVR). PVR was calculated using the following formula: $\mathrm{PVR}=(80 \mathrm{x}$ (Mean Pulmonary Arterial Pressure- Left Atrial Pressure))/Pulmonary Blood Flow. The right femoral artery and vein were exposed after surgical incision, and after heparin injection (30,000 IE), a 15 French cannula (Medtronic, Minneapolis, Minnesota, US) was inserted into the artery for infusion of blood from the extracorporeal system. Drainage to the system was achieved using a 21 French cannula (Medtronic, Minneapolis, Minnesota, US) inserted over a guide wire into the right jugular vein.

For extracorporeal circulation, we used a prototype centrifugal pump to drive the extracorporeal circulation through an oxygenator (QUADROX adult, Maquet, Rastatt, Germany). Oxygen flow to the oxygenator was set at a constant level of $2 \mathrm{~L} / \mathrm{min}$ with $100 \%$ oxygen. Extracorporeal blood flow was measured using an ultrasonic flowmeter (Sono TT, em-tec GmbH, Finning, Germany). The pump was initially set to 3000 rounds per minute (RPM), resulting in a mean flow of $2.4 \mathrm{~L} /$ min. By using two additional Y-connectors, a shunt in the external circulation was created, allowing us to initiate/stop external circulation quickly without tampering with pump settings. 
$\mathrm{CO}$ was delivered from a pressure cylinder with an attached pressure reduction valve. Through "air" tubes, $\mathrm{CO}$ gas was connected to 1) a $\mathrm{CO}$ monitor (Exhaust Emission Gas Analyser, Model SV-5Q, China Coal, Shaanxi, China) and 2) the research animal via the ventilator, forming a closed system to avoid leakage of $\mathrm{CO}$ into the operating theatre. When administering $\mathrm{CO}$, the valve was opened briefly with intervals to avoid overdosing and to keep the inhalation concentration at a level of approximately $1-2 \%$. CO administration was stopped permanently at the time of randomization. Conventional arterial blood gas analyses were made regularly using a blood gas analyser (ABL800 FLEX Series, Radiometer Medical, Brønshøj, Denmark), allowing us to track changes and to keep track of $\mathrm{HbCO}$ during the experiment. Constant $\mathrm{CO}$ monitoring with an alarm was used to secure the safety of laboratory personnel in the room.

\section{Experimental protocol}

Animals were randomly assigned to the study groups following simple randomization procedures (computerized random numbers) by a third party. Allocation concealment was kept blinded for the study personnel who were going to implement assignments at the time that cardiac failure was evident (defined as cardiac output decreased to $50 \%$ ), which was taken as a surrogate measure of severe $\mathrm{CO}$ intoxication. At this point, a sequential numbered, sealed, opaque envelope was opened. Blinding to the allocated arm was not possible due to the nature of the experiment. The primary outcome in the model was survival. The histological effect on lung tissue and changes in PVR were used as secondary outcomes.

Cardiac arrest, defined as systolic blood pressure below $25 \mathrm{mmHg}$, was treated using advanced resuscitation according to the 2015 guidelines of the European Resuscitation Council [21, 22]. However, chest compressions were replaced by internal cardiac compressions, and direct current defibrillation was attempted using internal paddles (Zoll Pro Pac MD, ZOLL Medical Corporation, Chelmsford, Massachusetts, US). If resuscitation failed in the ventilator group (defined as no return of spontaneous circulation (ROSC) and a lack of any signs of improvement in the condition within $10 \mathrm{~min}$ ), ECMO was established. Weaning from ECMO in both groups was not attempted until $\mathrm{HbCO}$ was less than $10 \%$. Weaning was not considered successful unless $10 \mathrm{~min}$ of off-pump circulation was completed without cardiac or respiratory failure. All animals were euthanized using pentobarbital intravenous injection after completion of the experiments.

Tissue samples of approximately eight $\mathrm{cm}^{3}$ were taken from the lungs close to the pleura at different sites prior to $\mathrm{CO}$ poisoning. Similar samples were taken after intoxication at the time of randomization. These samples were preserved using formalin and analysed microscopically at the Department of Forensic Medicine, Aarhus University, after slicing and staining with haematoxylin and eosin $(\mathrm{H} \& \mathrm{E})$.

\section{Statistical analysis}

We used the "resource equation" method for sample size calculation in the present study, as it was not possible to assume anything about the effect size or to determine standard deviations from previous studies [23]. According to this method, the value " $E$ " was measured by the following formula: $E=$ Total number of animals - Total number of groups. Any sample size that maintained " $E$ " between 10 and 20 was considered adequate. To avoid unnecessary wastage of resources and comply with ethical issues, we kept the number of animals included in this pilot study to six in each group, i.e., "E": $12-2=10$.

For statistical analysis, we used the open source freeware program R, version 3.4.3/R-studio and IBM SPSS, version 25. Group comparisons at baseline and at the point of randomization were made using an unpaired t-test. Tests for normality were performed by visual inspection of qq-plots of all variables and Levene's test for equality of variances. A paired-samples t-test was conducted to compare mean $\mathrm{pO}_{2}$ at baseline and mean $\mathrm{pO}_{2}$ at the point of randomization. A simple linear regression was constructed to predict $\mathrm{pO}_{2}$ based on $\mathrm{HbCO}$. Similarly, we constructed a linear regression to predict pulmonary vascular resistance (PVR) based on $\mathrm{HbCO}$ and PVR based on $\mathrm{pO}_{2}$. An exponential regression was performed to describe the correlation between lactate and $\mathrm{HbCO}$.

\section{Results}

There were no significant differences between the study groups at baseline (Table 1) and at the time of randomization (Table 2). The mean time of the duration of $\mathrm{CO}$ intoxication was $53 \mathrm{~min}$ : $51.0 \mathrm{~min}$ for the ECMO group $(\mathrm{SD}=13.3)$ and $56.5 \mathrm{~min}$ for the ventilator group $(\mathrm{SD}=14.8), p=0.97$.

All animals survived in the ECMO group for at least $10 \mathrm{~min}$ after weaning from ECMO once $\mathrm{HbCO}$ was below $10 \%$, although one had to be resuscitated due to a cardiac arrest that occurred immediately after the initiation of external circulation (ROSC after $17 \mathrm{~min}$ ). The mean time from the identification of heart failure to the initiation of ECMO treatment was $4.3 \mathrm{~min}$. Only one animal survived in the ventilator group, and five suffered from cardiac arrest at an average of $11.8 \mathrm{~min}$ after the initiation of treatment. It was not possible to resuscitate any of these animals by conventional means within 10 min of cardiac arrest. However, after initial resuscitation attempts were abandoned, we established ECMO treatment and successfully managed to resuscitate four of these animals (Fig. 1). No adverse events occurred. Time 
Table 1 Baseline characteristics

\begin{tabular}{|c|c|c|c|c|c|c|}
\hline & Ventila & & ECMO & & Differe & \\
\hline & & $\mathrm{Cl}(95 \%)$ & & $\mathrm{Cl}(95 \%)$ & & $P$-value \\
\hline Weight (kg) & 48.7 & $46.2-51.1$ & 47.5 & $44.5-50.5$ & 1.17 & 0.46 \\
\hline $\mathrm{HbCO}(\%)$ & 2.9 & $2.3-3.5$ & 3.2 & $2.5-3.8$ & -2.5 & 0.47 \\
\hline $\mathrm{pH}$ & 7.41 & $7.33-7.49$ & 7.42 & $7.36-7.47$ & -0.01 & 0.86 \\
\hline $\mathrm{Hb}(\mathrm{mmol} / \mathrm{L})$ & 4.58 & $4.08-5.09$ & 4.87 & $3.84-5.89$ & -0.28 & 0.54 \\
\hline $\mathrm{pCO}_{2}(\mathrm{kPa})$ & 5.37 & $4.85-5.88$ & 5.27 & $4.70-5.84$ & 0.10 & 0.75 \\
\hline $\mathrm{pO}_{2}(\mathrm{kPa})$ & 11.53 & $8.33-14.74$ & 10.68 & $9.58-11.78$ & 0.85 & 0.53 \\
\hline Lactate $(\mathrm{mmol} / \mathrm{L})$ & 1.23 & $0.72-1.75$ & 1.1 & $0.68-1.53$ & 0.13 & 0.62 \\
\hline Temperature $\left({ }^{\circ} \mathrm{C}\right)$ & 37.3 & $35.8-38.9$ & 37 & $36.6-37.5$ & 0.28 & 0.67 \\
\hline Cardiac output (L/min) & 3.45 & $2.77-4.13$ & 3.72 & $2.84-4.60$ & -0.27 & 0.55 \\
\hline MAP $(\mathrm{mmHg})$ & 78.5 & $62.9-94.1$ & 85.7 & $76.1-95.3$ & -7.2 & 0.34 \\
\hline HR (beats/min) & 71.2 & $47.5-94.8$ & 73.5 & $57.2-89.8$ & -2.3 & 0.84 \\
\hline MPAP (mmHg) & 24.5 & $23.1-26.0$ & 25.8 & $20.0-31.6$ & -1.3 & 0.58 \\
\hline MLAP $(\mathrm{mmHg})$ & 10.2 & $8.9-11.4$ & 10.5 & $9.4-11.6$ & -0.3 & 0.61 \\
\hline PVR (dyn.s/cm $\mathrm{cm}^{5}$ ) & 344.2 & $238.7-449.6$ & 325.2 & $248.8-401.5$ & 19 & 0.72 \\
\hline
\end{tabular}

The table shows baseline characteristics of essential values in the ventilator group vs the ECMO group. MAP Mean Arterial Pressure, HR Heart Rate, MPAP Mean pulmonary Pressure, MLAP Mean left atrial pressure, PVR Pulmonary Vascular resistance

on ECMO was $182.5 \mathrm{~min}(\mathrm{SD}=21.9)$ for the ECMO group and $201.6 \mathrm{~min}(\mathrm{SD}=63.5)$ for those in the ventilator group that ended up on ECMO after failure of conventional resuscitation, $p=0.96$. The mean time for $\mathrm{HbCO}$ to fall below 0.1 after intoxication was $123.7 \mathrm{~min}(\mathrm{SD}=20.0)$ for the ECMO group and 163.7 $\min (\mathrm{SD}=15.2)$ for the ventilator group, $p=0.56$.

Lactate concentrations in the blood increased exponentially as $\mathrm{HbCO}$ increased, $p<0.001\left(\mathrm{R}^{2}\right.$ of 0.562$)$ (Fig. 2a). A significant regression equation was found when comparing $\mathrm{pO}_{2}$ with $\mathrm{HbCO}, \mathrm{p}<0.001$, $\left(\mathrm{R}^{2}\right.$ of 0.496$)$. The predicted $\mathrm{pO}_{2}$ was equal to $109.2 \mathrm{mmHg}$ minus 10.4 $\mathrm{mmHg}$ for every $0.1 \%$ increase in $\mathrm{HbCO}$ (Fig. 2b). There was a significant difference in $\mathrm{pO}_{2}$, mean $83.1 \mathrm{mmHg}$ (95\% CI: 72.8-93.0) at baseline vs. mean $26.3 \mathrm{mmHg}$ (95\% CI: 20.3-26.3) at randomization, $p<0.001$. We did not find a significant linear regression equation, $p=0.54$ $\left(R^{2}=0.008\right)$ when exploring the association between PVR and $\mathrm{HbCO}$ (Fig. 2c). However, mean PVR was the lowest at $\mathrm{HbCO}=54 \%$ corresponding to a mean PVR of 200

Table 2 Characteristics at point of randomization

\begin{tabular}{|c|c|c|c|c|c|c|}
\hline & \multicolumn{2}{|c|}{ Ventilator $(n=6)$} & \multicolumn{2}{|c|}{$\mathrm{ECMO}(n=6)$} & \multicolumn{2}{|c|}{ Difference } \\
\hline & & $\mathrm{Cl}(95 \%)$ & & $\mathrm{Cl}(95 \%)$ & & $P$-value \\
\hline $\mathrm{HbCO}(\%)$ & 69.7 & $59.4-80.0$ & 67.9 & $49.6-86.2$ & -2.0 & 0.83 \\
\hline $\mathrm{pH}$ & 7.26 & $7.16-7.36$ & 7.31 & $7.23-7.39$ & -0.05 & 0.34 \\
\hline $\mathrm{Hb}(\mathrm{mmol} / \mathrm{L})$ & 5.85 & $4.98-6.72$ & 6.17 & $5.21-7.12$ & -0.32 & 0.54 \\
\hline $\mathrm{pCO}_{2}(\mathrm{mmHg})$ & 37.7 & $29.0-46.4$ & 39.2 & $34.4-44.0$ & -1.4 & 0.72 \\
\hline $\mathrm{pO}_{2}(\mathrm{mmHg})$ & 34.5 & $21.5-47.6$ & 24.4 & $17.4-31.4$ & 10.1 & 0.12 \\
\hline Lactate (mmol/L) & 7.33 & $6.45-8.22$ & 6.27 & $5.27-7.26$ & 1.07 & 0.07 \\
\hline Temperature $\left({ }^{\circ} \mathrm{C}\right)$ & 37.4 & $36.1-38.8$ & 37.1 & $36.4-37.7$ & 0.35 & 0.56 \\
\hline Cardiac output (L/min) & 1.57 & $1.17-1.96$ & 1.34 & $0.43-2.25$ & 0.23 & 0.57 \\
\hline$\%$ of base line & 49.5 & $37.5-61.4$ & 41.33 & $6.39-76.26$ & 8.13 & 0.59 \\
\hline MAP (mmHg) & 46.3 & $35.1-57.6$ & 38.8 & $32.3-45.4$ & 7.5 & 0.18 \\
\hline HR (beats/min) & 102.5 & $74.8-130.2$ & 108.17 & $84.4-131.9$ & -5.67 & 0.70 \\
\hline MPAP (mmHg) & 20,0 & $16.6-23.5$ & 16.2 & $12.5-19.8$ & 3.83 & 0.08 \\
\hline MLAP (mmHg) & 8.2 & $5.6-10.8$ & 7.8 & $5.4-10.3$ & 0.33 & 0.82 \\
\hline PVR (dyn.s.cm $\mathrm{cm}^{-5}$ ) & 657.3 & $316.2-998.5$ & 579.8 & 207.8-951.9 & 77.5 & 0.70 \\
\hline
\end{tabular}

The table shows characteristics of essential values at point of randomization in the ventilator group vs the ECMO group. MAP Mean Arterial Pressure, HR Heart Rate, MPAP Mean pulmonary Pressure, MLAP Mean left atrial pressure, PVR Pulmonary Vascular resistance 


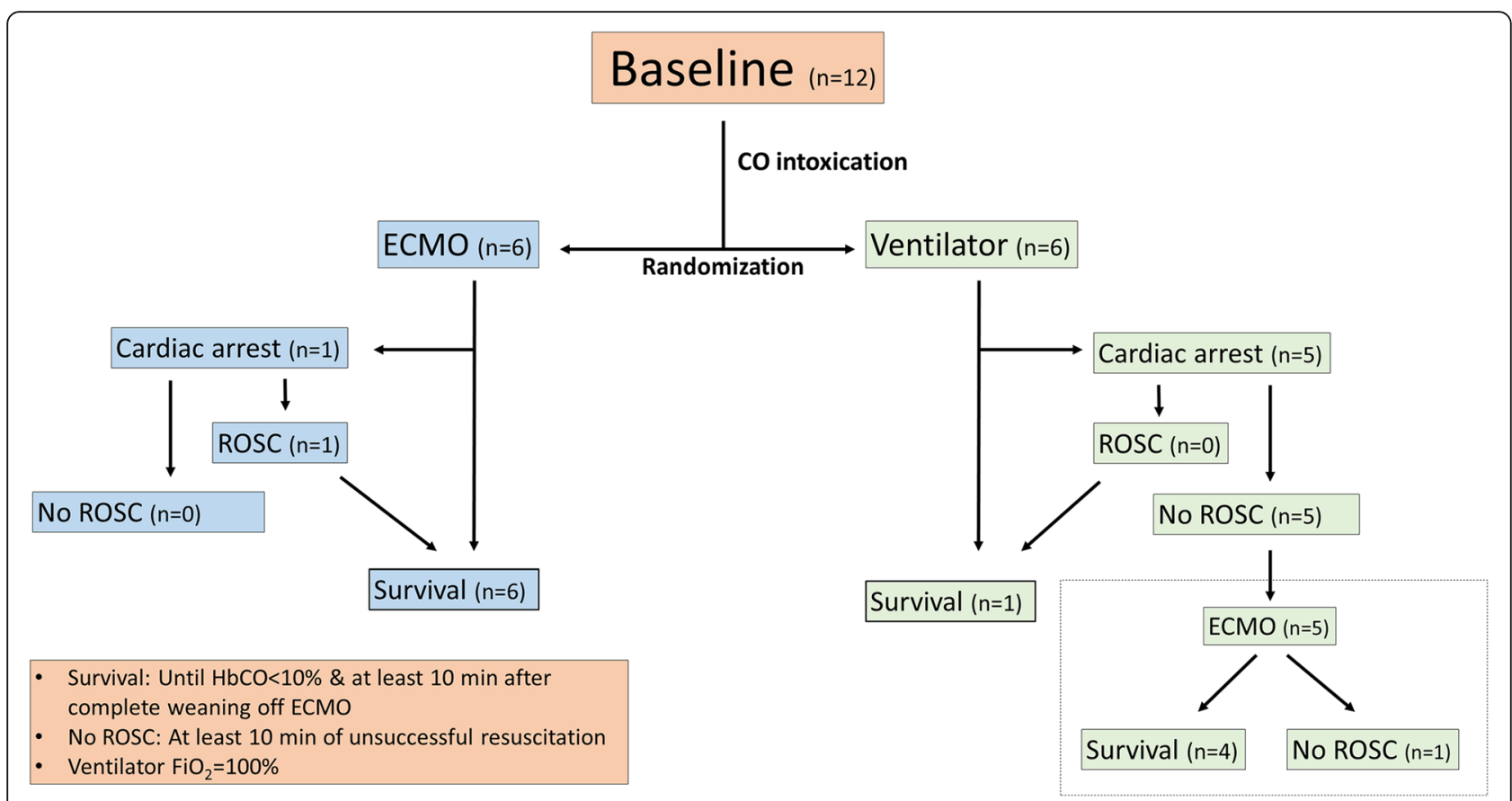

Fig. 1 Flowchart of survival. ECMO = Extracorporeal membrane oxygenation, ROSC = Return of spontaneous circulation

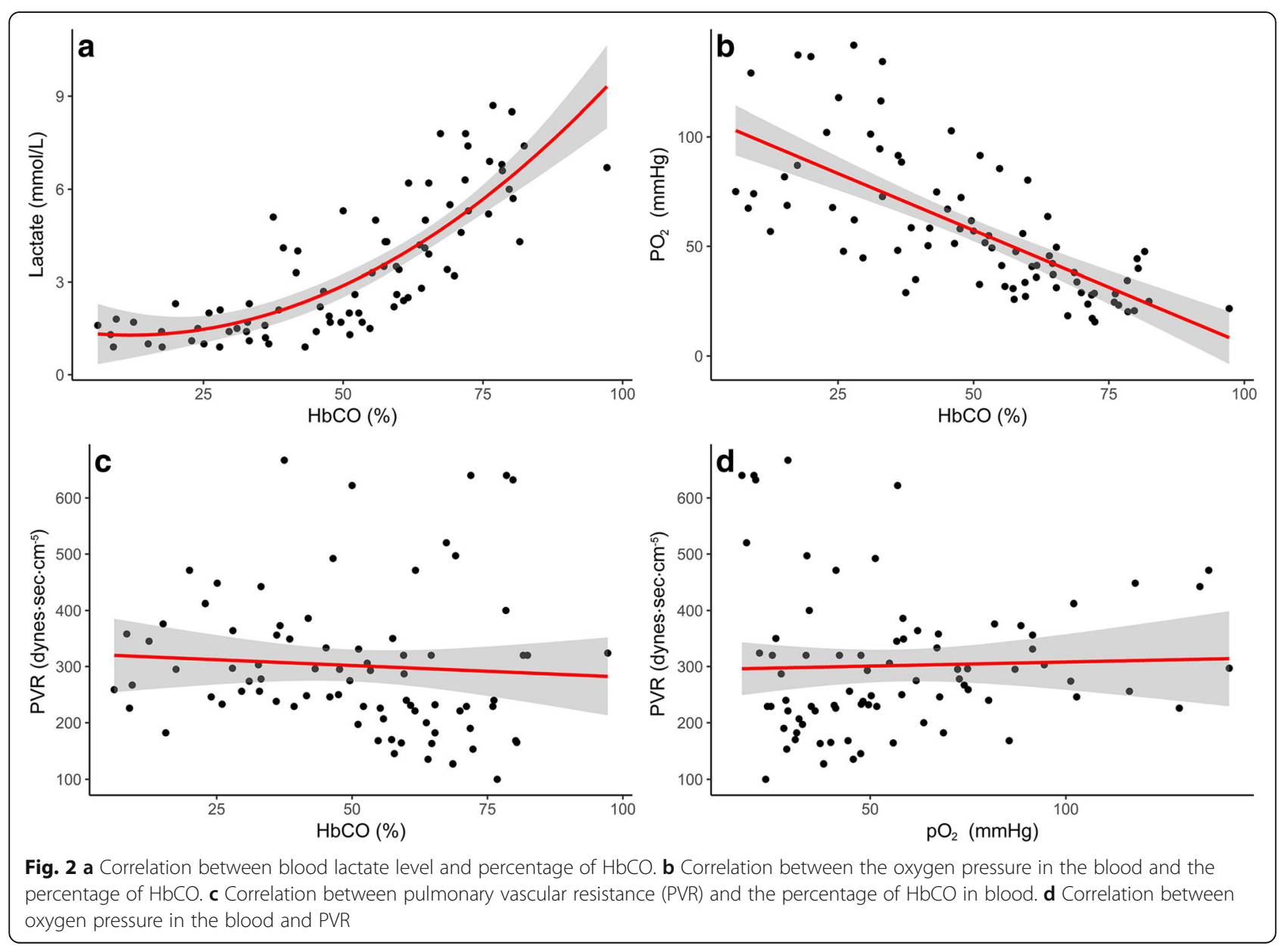


dyn.s $/ \mathrm{cm}^{5}$ (95\% CI: 148-252) compared to the baseline mean PVR of 319 dyn.s $/ \mathrm{cm}^{5}$ (95\% CI: 261-378) (Fig. 3a). This difference was statistically significant $(\mathrm{p}<0.001)$. No correlation was found between $\mathrm{pO}_{2}$ and PVR, $p=0.76$ $\left(R^{2}=-0.001\right)$ (Fig. 2d). Regarding the highest achieved $\mathrm{pO}_{2}$ dependent on treatment, the highest $\mathrm{pO}_{2}$ on ECMO was $551.3 \mathrm{mmHg}$ (95\% CI: 487.5-615.0) versus the highest $\mathrm{pO}_{2}$ on a ventilator at $99.8 \mathrm{mmHg}$ (95\% CI: $\left.0-283.5\right)$ (Fig. 3b). In surviving animals, we were able to increase $\mathrm{pO}_{2}$ from a mean of $27.0 \mathrm{mmHg}$ (95\% CI: $19.5-30.8$ ) at the time of randomization to a mean of $209.3 \mathrm{mmHg}$ (95\% CI: 102.8-315.0), $p=0.003$.

There were no microscopic differences in H\&E-stained lung tissue biopsies obtained prior to $\mathrm{CO}$ intoxication versus after (Fig. 4). No intra-alveolar fluid accumulation and no signs of inflammation were evident.

\section{Discussion}

In this study, we showed that ECMO treatment in severe cases of $\mathrm{CO}$ poisoning greatly improved survival compared with conventional resuscitation in an experimental porcine model. Thus, ECMO may serve as a treatment option in addition to conventional treatment following severe $\mathrm{CO}$ poisoning. The use of $\mathrm{HBO}$ is only possible in a limited number of hospitals within each country, and treatment can only be offered to a fraction of the population without the need for interhospital transportation. In contrast, ECMO treatment is available in mobile systems and can be transferred to the patients [24]. In Denmark, a highly mobile ECMO team exists, using helicopter assets from the Royal Danish Airforce when needed to reduce transport time.

The increased probability of survival, even following cardiac arrest and resuscitation, underlines ECMO treatment's ability to stabilize respiratory and cardiac function while proper restitution occurs. For practical reasons, we weaned the animals from ECMO as soon as $\mathrm{HbCO}$ was below $0.1 \%$. In real clinical settings, more time would probably be advisable to allow for more complete restitution. We chose $10 \mathrm{~min}$ post-weaning as marker for survival because in our experience, subsequent circulatory failure would probably reoccur during this timeframe.

A large proportion of CO-poisoned patients may suffer from lung injuries from other components in smoke (e.g., nitrogen oxide gasses, hydrogen chloride) and thermal injuries from the inhalation of hot gases. In these cases, the benefits of ECMO would potentially be even greater, as current treatment with a ventilator and/or HBO rely on the lung diffusion capacity to ensure sufficient oxygen tension in the blood.

In a study of 18 patients who suffered from cardiac arrest due to $\mathrm{CO}$ poisoning, none of the patients who were subjected to $\mathrm{HBO}$ treatment after resuscitation survived hospitalization [14]. The authors concluded that "the prognosis of this condition should be considered when making triage and treatment decisions for patients poisoned to this severity", implying that the termination of treatment should be considered if cardiac arrest occurs in this patient category. The cause of this negative outcome may be explained by pulmonary insufficiency due to inhalation injuries from smoke/heat that make efficient gas exchange impossible, and a case report from 2017 indicated that patients with pulmonary insufficiency might experience longer $\mathrm{HbCO}$ half-life, diminishing the possible positive benefits of HBO treatment [25]. The results of the present study imply that survival may be possible if ECMO can be established.

The benefits of ECMO may be explained by the release of strain on the heart, lowering oxygen consumption and allowing sufficient restitution following ischaemia. Another favourable effect of using ECMO is

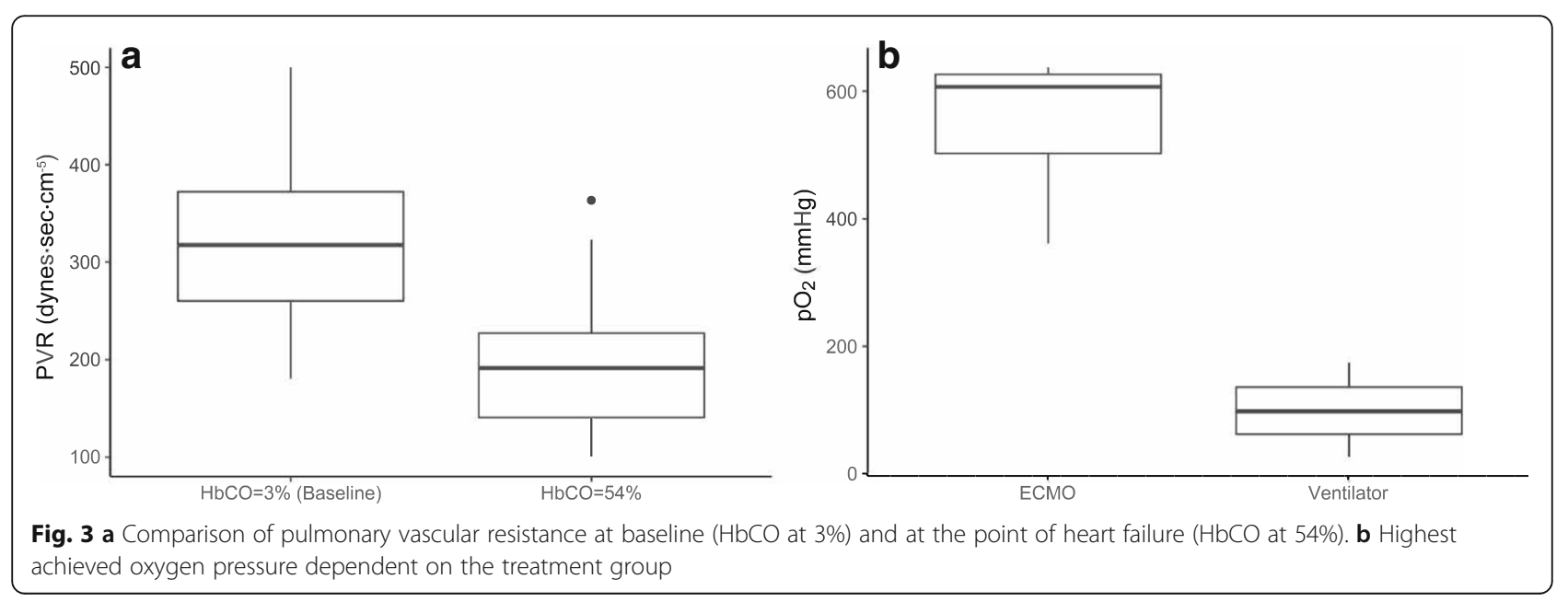



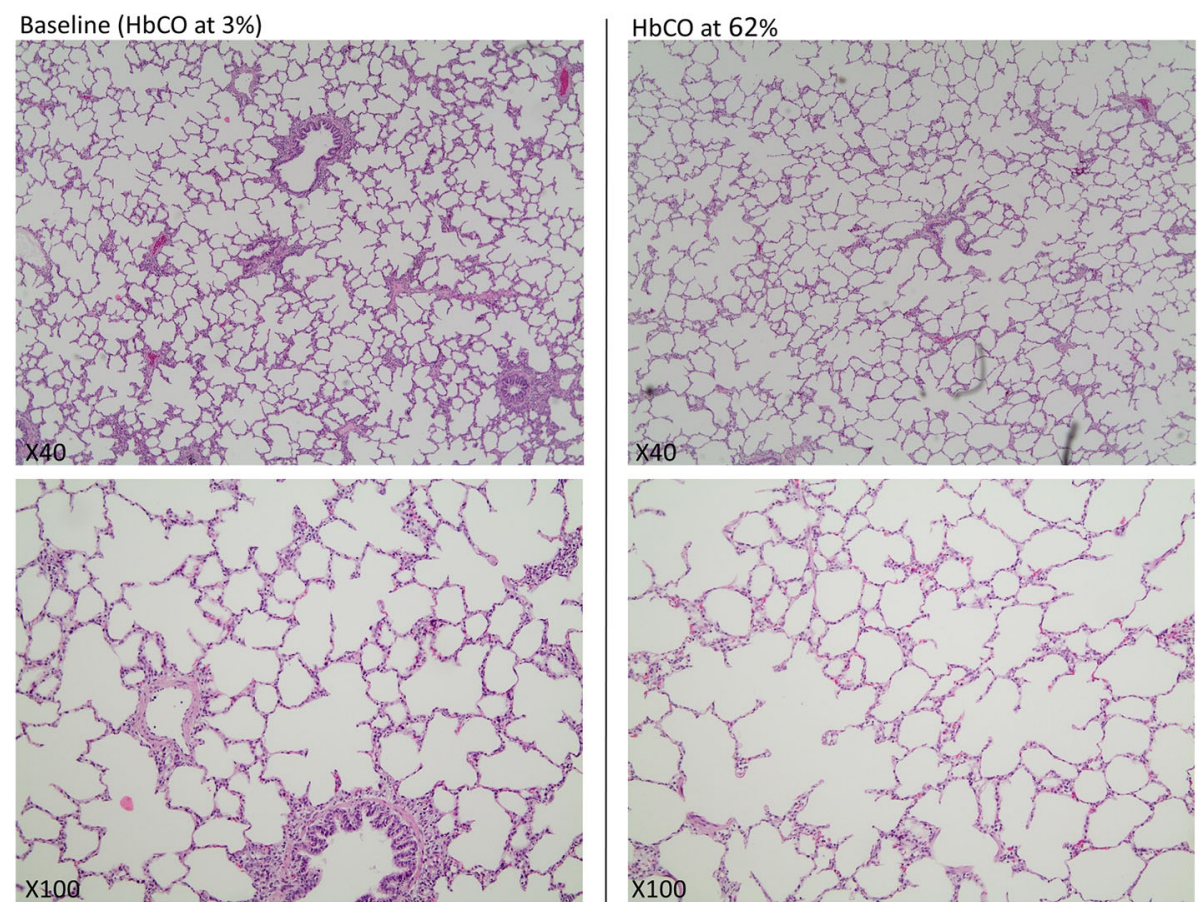

Fig. 4 Representative haematoxylin and eosin-stained slices of lung tissue at baseline and at a high level of CO intoxication

its non-dependence on the condition of the lungs and airways. ECMO has the potential to increase blood oxygen tension, diminishing ischaemia and favouring increased formation of oxyhaemoglobin and elimination of $\mathrm{CO}$.

Prior to the experiments, we expected that PVR would increase during $\mathrm{CO}$ poisoning, contributing to cardiac insufficiency through a backward failure mechanism. However, this was not the case as the trend was towards a lower PVR during CO poisoning. It is possible that this can be explained by hypoxia induction of the relaxation of smooth muscle cells in resistance vessels in the pulmonary system, but separate experiments must be undertaken to clarify this. To the best of our knowledge, no previous studies regarding changes in PVR due to $\mathrm{CO}$ poisoning have been published.

We found a negative linear correlation between $\mathrm{HbCO}$ and $\mathrm{O}_{2}$. Our initial presumption was that this might be due to a negative impact on the lung tissue, especially the diffusion barrier, making $\mathrm{O}_{2}$ absorption progressively harder. This was not supported by the histological findings on the lung biopsies obtained prior to $\mathrm{CO}$ poisoning and compared individually with biopsies obtained after $\mathrm{CO}$ poisoning; no consistent differences were detected. The answer may be found on a molecular level, undetectable by the analysis of this experiment. Another hypothesis may be that $\mathrm{CO}$ causes shunting in the lungs, which is supported by our finding of decreased PVR.

Promising experiments have been made using light to decrease HbCO's half-life, and it would be simple to expose the oxygenator in the ECMO system to a strong source of light [26]. Other experiments have used $\mathrm{O}_{3}$ instead of $\mathrm{O}_{2}$ as oxygen supply to the oxygenator in the external circulation to decrease HbCO's half-life [27]. Some patients suffering from $\mathrm{CO}$ poisoning due to inhaling smoke will also suffer from cyanide poisoning [28]. A specific antidote for cyanide may be administered while ECMO stabilizes the patient, the effects of both $\mathrm{CO}$ and Cyanide diminish and the patient recovers.

A limitation of this study is that all animals were sacrificed at the end of the experiment due to ethical reasons. Thus, we had no ability to evaluate any neurological outcomes. Additionally, long-term mortality and morbidity could not be evaluated. In two case reports regarding successful ECMO support of patients suffering from severe $\mathrm{CO}$ poisoning with insufficient response to traditional ventilator therapy, no neurological deficits were detected during follow-up [29, 30]. There may be a theoretical risk of bias if efforts for resuscitation differed between study groups. However, we have no reason to believe this was the case as we strictly followed published resuscitation algorithms in both groups. 
Precautions must be taken when inferring results from animal studies to human clinical settings; nevertheless, since this study involved large animals, we speculate that similar results may be obtained when humans are treated. Furthermore, the benefits of using ECMO must be weighed against the risk of potential complications.

\section{Conclusion}

The use of VA-ECMO following severe cases of CO poisoning with cardiogenic shock greatly improved short-term survival compared with conventional resuscitation in an experimental porcine model. This study forms the basis for further research among patients.

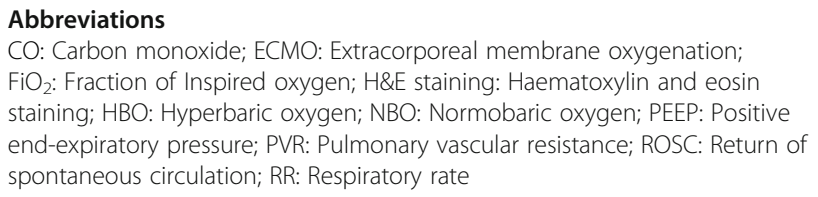

\section{Acknowledgements}

Not applicable

\section{Ethical approval and consent to participate}

This study was carried out in accordance with Danish and European legislation regarding the use of animals for research purposes. The experiments were approved by the Danish Animal Experiments Inspectorate (J.nr. 2016-15-0201-01064). At all times, a veterinarian was present, and all participants had training in laboratory animal science prior to the experiments.

\section{Funding}

This research received funding from "Brødrene Hartmanns Fond". Additional funding was received from the Research Fund of the Department of Cardiothoracic Surgery at Aalborg University Hospital.

\section{Availability of data and materials}

The datasets used and/or analysed during the current study are available from the corresponding author on reasonable request.

\section{Authors' contributions}

CS Literature search, data collection, study design, analysis of data, manuscript preparation, review of manuscript. SOM Literature search, data collection, study design, manuscript preparation, analysis of data, review of manuscript. JJA Literature search, data collection, study design, analysis of data, manuscript preparation, review of manuscript. MCR Analysis of data (especially microscopic evaluation of lung biopsies), manuscript preparation, review of manuscript. BK Literature search, data collection, study design, analysis of data, manuscript preparation, review of manuscript. All authors read and approved the final manuscript.

\section{Consent for publication}

Not applicable

\section{Competing interests}

The authors declare that they have no competing interests.

\section{Publisher's Note}

Springer Nature remains neutral with regard to jurisdictional claims in published maps and institutional affiliations.

\section{Author details}

'Department of Cardiothoracic Surgery, Aalborg University Hospital, Hobrovej 18-22, 9000 Aalborg, Denmark. ${ }^{2}$ Department of Clinical Medicine, Aalborg
University, Sdr. Skovvej 15, 9000 Aalborg, Denmark. ${ }^{3}$ Biomedical Research Laboratory, Aalborg University Hospital North, Ladegårdsgade 3, 9000 Aalborg, Denmark. ${ }^{4}$ Department of Forensic Medicine, Aarhus University, Palle Juul-Jensens Boulevard 99, 8200 Aarhus, Denmark.

Received: 8 July 2018 Accepted: 14 November 2018

Published online: 22 November 2018

\section{References}

1. Gormsen $\mathrm{H}$, Jeppesen $\mathrm{N}$, Lund A. The causes of death in fire victims. Forensic Sci Int. 1984;24(2):107-11.

2. Li F, Chan HC, Liu S, Jia H, Li H, Hu Y, et al. Carbon monoxide poisoning as a cause of death in Wuhan, China: a retrospective six-year epidemiological study. Forensic Sci Int. 2015;253:112-8.

3. Thomsen $\mathrm{AH}$, Gregersen M. Carbon monoxide deaths caused by town gas in Denmark 1995-99. Dan Med Bull. 2007;169(21):2020-4.

4. Thomsen AH, Gregersen M. Suicide by carbon monoxide from car exhaustgas in Denmark 1995-1999. Forensic Sci Int. 2006;161(1):41-6.

5. Nielsen PR, Gheorghe A, Lynnerup N. Forensic aspects of carbon monoxide poisoning by charcoal burning in Denmark, 2008-2012: an autopsy based study. Forensic Sci Med Pathol. 2014;10(3):390-4

6. Hampson NB, Weaver LK. Carbon monoxide poisoning: a new incidence for an old disease. Undersea Hyperb Med. 2007;34(3):163-8.

7. Hampson NB, Hauff NM. Risk factors for short-term mortality from carbon monoxide poisoning treated with hyperbaric oxygen. Crit Care Med. 2008; 36(9):2523-7.

8. Tapeantong T, Poungvarin N. Delayed encephalopathy and cognitive sequelae after acute carbon monoxide poisoning: report of a case and review of the literature. J Med Assoc Thail. 2009;92(10):1374-9.

9. Al-Moamary MS, Al-Shammary AS, Al-Shimemeri AA, Ali MM, Al-Jahdali HH, Awada AA. Complications of carbon monoxide poisoning. Saudi Med. 2000; 21(4):361-3.

10. Lee FY, Chen WK, Lin CL, Kao CH. Carbon monoxide poisoning and subsequent cardiovascular disease risk: a nationwide population-based cohort study. Medicine (Baltimore). 2015;94(10):e624.

11. Guzman JA. Carbon Monoxide Poisoning. Crit Care Clin. 2012;28(4):537-48

12. Weaver LK, Howe S, Hopkins R, Chan KJ. Carboxyhemoglobin half-life in carbon monoxide-poisoned patients treated with 100\% oxygen at atmospheric pressure. Chest. 2000;117(3):801-8.

13. Mutluoglu M, Metin S, Arziman I, Uzun G, Yildiz S. The use of hyperbaric oxygen therapy for carbon monoxide poisoning in Europe. Undersea Hyperb. Med. 2016;43(1):49-56.

14. Hampson NB, Zmaeff JL. Outcome of patients experiencing cardiac arrest with carbon monoxide poisoning treated with hyperbaric oxygen. Ann Emerg Med. 2001;38(1):36-41.

15. Yanir Y, Shupak A, Abramovich A, Reisner SA, Lorber A. Cardiogenic shock complicating acute carbon monoxide poisoning despite neurologic and metabolic recovery. Ann Emerg Med. 2002;40(4):420-4.

16. Buckley NA, Juurlink DN, Isbister G, Bennett MH, Lavonas EJ. Hyperbaric oxygen for carbon monoxide poisoning. Cochrane Database Syst Rev. 2011; 13(4):CD002041.

17. Huang CC, Ho CH, Chen YC, Lin HJ, Hsu CC, Wang JJ, Su SB, et al. Hyperbaric oxygen therapy is associated with lower short- and longterm mortality in patients with carbon monoxide poisoning. Chest. 2017;152(5):943-53

18. Swindle MM, Makin A, Herron AJ, Clubb FJ, Frazier KS. Swine as models in biomedical research and toxicology testing. Vet Pathol. 2012;49(2): 344-56.

19. Swindle MM, Smith AC. Swine in the Laboratory : surgery, anesthesia, imaging, and experimental techniques. 3rd edition. Florida:CRC Press;2015.

20. Flecknell, P. A. Laboratory animal Anaesthesia. 4th edition. Massachusetts: Elsevier|Academic Press;2009.

21. Idris AH, Becker LB, Ornato JP, Hedges JR, Bircher NG, Chandra NC, et al. Utstein-style guidelines for uniform reporting of laboratory CPR research. A statement for healthcare professionals from a task force of the American Heart Association, the American College of Emergency Physicians, the American College of Cardiology, the European resuscitation council, the Heart and Stroke Foundation of Canada, the Institute of Critical Care Medicine, the Safar Center for Resuscitation Research, and the Society for Academic Emergency Medicine. Circulation. 1996;94(9):2324-36. 
22. Soar J, Nolan JP, Böttiger BW, Perkins GD, Lott C, Carli P, et al. European resuscitation council guidelines for resuscitation 2015. Section 3. Adult advanced life support. Resuscitation. 2015;95:100-47.

23. Charan J, Kantharia ND. How to calculate sample size in animal studies? J Pharmacol Pharmacother. 2013;4(4):303-6.

24. Lamhaut L, Hutin A, Puymirat E, Jouan J, Raphalen JH, Jouffroy R, et al. A pre-hospital extracorporeal cardio pulmonary resuscitation (ECPR) strategy for treatment of refractory out hospital cardiac arrest: an observational study and propensity analysis. Resuscitation. 2017;117:109-17.

25. Weaver LK, Deru K. Carboxyhemoglobin half-life during hyperbaric oxygen in a patient with lung dysfunction: a case report. Undersea Hyperb. Med. 2017:44(2):173-7.

26. Zazzeron L, Liu C, Franco W, Nakagawa A, Farinelli WA, Bloch DB, et al. Pulmonary phototherapy for treating carbon monoxide poisoning. Am J Respir Crit Care Med. 2015:192(10):1191-9.

27. Yin L, Cai Q, Zhen Q, Chen Z, Li F, Yan P, et al. Treatment of acute carbon monoxide poisoning with extracorporeal membrane trioxygenation. Int J Artif Organs. 2012;35(12):1070-6.

28. Grabowska T, Skowronek R, Nowicka J, Sybirska H. Prevalence of hydrogen cyanide and carboxyhaemoglobin in victims of smoke inhalation during enclosed-space fires: a combined toxicological risk. Clin Toxicol. 2012;50(8):759-63.

29. Wang Y, Chen C, Chian C, Perng W. Extracorporeal membrane oxygenation for Management of Carbon Monoxide Intoxication. J Med Sci. 2010;30(3):101-5.

30. Teerapuncharoen K, Sharma NS, Barker AB, Wille KM, Diaz-Guzman E. Successful treatment of severe carbon monoxide poisoning and refractory shock using extracorporeal membrane oxygenation. Respir Care. 2015;60(9):155-60

Ready to submit your research? Choose BMC and benefit from:

- fast, convenient online submission

- thorough peer review by experienced researchers in your field

- rapid publication on acceptance

- support for research data, including large and complex data types

- gold Open Access which fosters wider collaboration and increased citations

- maximum visibility for your research: over $100 \mathrm{M}$ website views per year

At $\mathrm{BMC}$, research is always in progress.

Learn more biomedcentral.com/submissions 